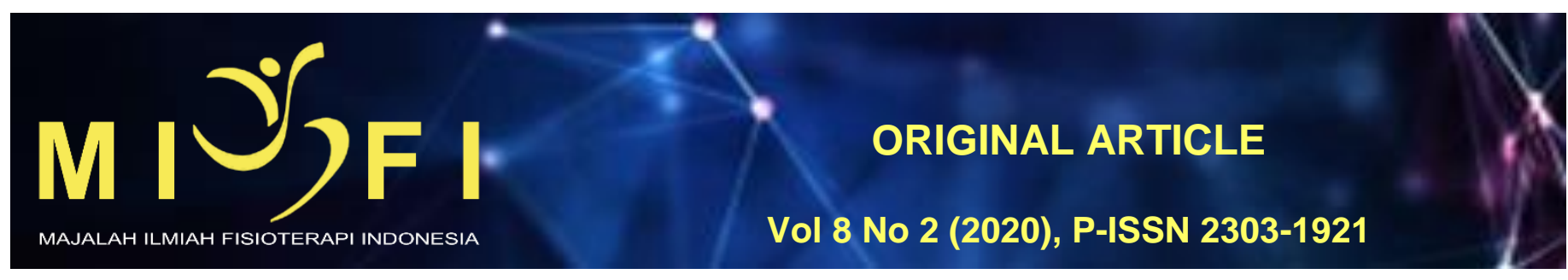

\title{
HUBUNGAN KEMAMPUAN KOGNITIF DENGAN KECEPATAN WAKTU REAKSI AUDITORI PADA REMAJA TINGKAT SEKOLAH MENENGAH ATAS NEGERI DI DENPASAR TIMUR
}

\author{
Ni Putu Ayu Dika Utami ${ }^{1}$, Ni Komang Ayu Juni Antari ${ }^{2}$, Ni Wayan Tianing ${ }^{3}$, Putu Ayu Sita Saraswati ${ }^{2}$ \\ ${ }^{1}$ Program Studi Sarjana Fisioterapi dan Profesi Fisioterapi, Fakultas Kedokteran Universitas Udayana \\ ${ }^{2}$ Departemen Fisioterapi, Fakultas Kedokteran Universitas Udayana \\ ${ }^{3}$ Departemen Biokimia, Fakultas Kedokteran Udayana \\ ayudikautami@gmail.com
}

\begin{abstract}
ABSTRAK
Masa remaja merupakan masa seorang remaja mulai belajar bertanggung jawab atas keputusannya sendiri dan bisa menyelesaikan masalah dengan baik sehingga memerlukan kemampuan kognitif dan waktu reaksi auditori yang baik. Tujuan penelitian ini untuk mengetahui hubungan kemampuan kognitif dengan kecepatan waktu reaksi auditori pada remaja tingkat sekolah menengah atas negeri di Denpasar timur. Penelitian ini merupakan penelitian analisis observasi dengan desain studi cross sectional. Penelitian ini dilakukan pada bulan Februari 2019 di SMAN 3 Denpasar dengan jumlah sampel 51 siswa dengan menggunakan metode cluster sampling. sampel diukur dengan menggunakan cognitive failure questionnaire (CFQ) lalu menggunakan tes waktu reaksi auditori yaitu millisecond software (simple auditory reaction time). Anilisis yang digunakan adalah analisi bivariat dengana uji pearson. Hasil analisis bivariat menunjukkan nilai $p=0,017$ dan $r=0,334$ artinya bahwa adanya hubungan yang signifikan antara kemampuan kognitif dengan kecepatan waktu reaksi auditori pada remaja tingkat sekolah menengah atas negeri di Denpasar timur namun memiliki hubungan yang rendah atau lemah.
\end{abstract}

Kata kunci: kognitif, waktu reaksi, auditori, remaja

\section{THE RELATIONSHIP OF COGNITIVE ABILITY WITH THE SPEED OF AUDITORY REACTIONS TIME IN YOUTH LEVELS OF PUBLIC HIGH SCHOOL IN EAST DENPASAR}

\section{ABSTRACT}

Adolescence is a period of a teenager who begin to learn to be responsible for his own decisions and solve the problems that require good cognitive ability and auditory reaction time. The purpose of this study to determine the relationship of cognitive abilities with speed auditory reaction time in young high- goverment school level in east Denpasar. This research used an analytical observation with cross sectional study design. This study was conducted in February 2019 at SMAN 3 Denpasar with 51 students as a sample by using cluster sampling method. the sample was measured by using cognitive failure questionnaire (CFQ) and then use the auditory reaction time test that is millisecond software (simple auditory reaction time). The analysis that used in this study were bivariate analysis with Pearson test. The results of the bivariate analysis showed the value of $p=0.017$ and $r=0.334$ means there is a significant correlation between cognitive ability with speed auditory reaction time in young high- Government School level of East Denpasar however it has low or weak relation.

Keywords: cognitive, reaction time, auditory, teenager

\section{PENDAHULUAN}

Remaja merupakan generasi muda sebagai penerus bangsa. Definisi remaja menurut peraturan Menteri kesehatan republik Indonesia nomor 25 (2014) disebut pada pasal 1 ayat 7 bahwa remaja adalah kelompok umur 10 tahun sampai umur 18 tahun Masa ini seseorang sudah mampu berpikir abstrak mereka sudah mampu memahami objek tanpa objek tersebut harus ada didepan mereka, sudah mampu berpikir logis untuk menyusun rencana guna untuk menyelesaikan masalah dan mereka sudah mampu berpikir idealis. ${ }^{1}$

Masa remaja dianggap sebagai periode penting karena banyak perubahan yang terjadi dari perubahan fisik atau mental yang akan berpengaruh pada individu itu sendiri, masa remaja juga dianggap sebagai periode peralihan dari masa anak-anak menuju masa dewasa artinya sifat pada masa anak-anak harus mulai ditinggalkan, masa remaja sebagai periode perubahan baik perubahan emosi, perubahan tubuh, minat, pola perilaku, bersikap ambivalen pada perubahan mereka ingin bebas namun takut dengan kemampuan yang dimiliki untuk dapat bertanggung jawab mengatasi kebebasan tersebut, masa remaja juga sebagai periode bermasalah yang paling sering dialami oleh remaja, masa remaja sebagai masa mencari identitas karena cenderung menyesuaikan diri dengan lingkungan dibandingkan diri sendiri namun seiring waktu remaja akan memiliki identitas diri masing-masing yang khas, masa remaja sebagai usia yang menimbulkan ketakutan karena remaja cenderung tidak simpatik dan takut untuk bertanggung jawab, masa remaja sebagai usia yang tidak realistic karena emosi yang labil dan belum matang, masa menuju masa dewasa yaitu perlu arahan dari orang yang berpengalaman karena disatu sisi mereka ingin menyesuaikan diri menjadi dewasa namun dilain sisi mereka tidak ingin melepaskan masa remaja. ${ }^{2}$ 
Kemampuan kognitif pada masa remaja sudah mengalami kemajuan dibanding dengan masa anak-anak dan dari segi struktur mulai mencapai kematangan yang optimal. Tahap ini terjadi perkembangan penalaran dan kemampuan berpikir. Potensi kualitas penalaran dan berpikir berkembang secara maksimum. Masa remaja juga merupakan masa menuju dewasa pada masa ini seseorang sudah mulai belajar bertanggung jawab dan menyelesaikan masalahnya sendiri.

Masalah yang umumnya ditemui remaja yaitu masalah di sekolah dan masalah di luar sekolah antara lain masalah disekolah yaitu ujian sekolah, kurikulum yang lebih berat, metode belajar yang kurang sesuai, mulai

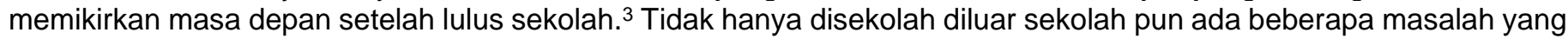
mereka temui seperti mulai terjadi perubahan postur tubuh dimana sudah terjadi perubahan kelamin sekunder, mulai mengenal lawan jenis, adaptasi dengan lingkungan yang luas, masalah pergaulan dan masalah lainnya. ${ }^{4}$

Menurut penelitian yang dilakukan oleh putri tahun 2014 prevalensi stres pada remaja dengan stres ringan sebesar $51,8 \%$, stres sedang sebesar $36,9 \%$ dan stres berat sebesar $11,3 \% .{ }^{5}$ Remaja sangat rentan terkena stress. Imbas dari stres tersebut akan berdampak pada prestasi siswa disekolah termasuk dalam hal penyelesaian tugas tugas disekolah. Penyelesaian tugas-tugas tersebut memerlukan kognitif yang baik dan waktu reaksi yang cepat dan tepat sehingga perlu mengetahui tingkat kognitif dan waktu reaksi auditori karena jika seseorang berpikir tanpa bertindak sama dengan seseorang tidak melakukan apapun terhadap masalahnya begitu juga saat seseorang hanya bertindak tanpa berpikir maka sama saja dengan menambah masalah karena mereka tidak memikirkan risiko yang mungkin bisa terjadi.

Kemampuan kognitif dan kecepatan waktu reaksi perlu untuk diketahui khusunya untuk remaja karena bermanfaat untuk meningkatkan prestasi siswa disekolah untuk meningkatkan prestasi siswa dan menyelesaikan masalah dengan respon yang cepat dan sesuai. Waktu reaksi adalah kemampuan seseorang untuk merespon stimulus yang datang baik suara, cahaya atau sentuhan dengan waktu secepat-cepatnya. ${ }^{6}$ Pengertian kognitif adalah pemahaman yang mengarah pada semua aktifitas mental seseorang yang berkaitan terhadap proses berpikir, memahami dan mengingat suatu hal. ${ }^{7}$

Faktor-faktor yang mempengaruhi perkembangan kognitif yaitu faktor keturunan dimana tiap individu sudah membawa potensinya masing-masing sejak dilahirkan, faktor lingkungan yaitu ditentukan oleh pengalaman dan pengetahuan yang diperoleh dari lingkungannya, faktor kematangan organ fisik dimana organ telah sanggup menjalankan fungsi masing-masing dikaitkan dengan umur kronologis seseorang, faktor pembentukan yaitu dapat dibentuk melalui sekolah atau mendapat pengaruh dari alam sekitar, faktor minat dan bakat jika seseorang memiliki minat dan bakat tertentu maka akan lebih mempelajari hal tersebut dan faktor kebebasan yaitu kebebasan dalam memilih dan menyelesaikan masalah dapat membentuk kognitif seseorang. ${ }^{8}$

Waktu reaksi memiliki tiga stimulus yaitu waktu reaksi auditori, waktu reaksi visual dan waktu reaksi taktil. ${ }^{9}$ Waktu reaksi juga memiliki tiga jenis yaitu waktu reaksi sederhana dimana terdapat satu stimulus dan akan menghasilkan satu stimulus, waktu reaksi pengenalan yaitu terdapat lebih dari satu stimulus dan responden harus memilih stimulus yang harus direspon dan diabaikan, ${ }^{10}$ waktu reaksi pilihan yaitu terdapat lebih dari satu stimulus dan juga respon yang diberikan bisa lebih dari satu. ${ }^{9}$

Faktor- faktor yang dapat mempengaruhi kecepatan waktu reaksi yaitu umur karena semakin tua maka kecepatan waktu reaksi akan ikut menurun, jenis kelamin juga mempengaruhi, pada laki-laki waktu reaksi akan lebih cepat karena pengaruh dari hormon, faktor latihan juga berpengaruh karena semakin sering seseorang berlatih kecepatan waktu reaksi maka hasil yang didapat akan semakin cepat, faktor kelelahan pun berpengaruh karena semakin lelah maka waktu reaksi akan semakin lambat, faktor obat-obatan dapat berpengaruh karena dapat mempengaruhi sistem saraf pusat, faktor makanan atau minuman seperti yang mengandung kafein karena dapat menurunkan kecepatan waktu reaksi, faktor alkohol karena dapat memperlambat aktivasi otot, faktor olahraga karena otot-otot yang terlatih, faktor gangguan seperti kebisingan karena akan mengganggu konsentrasi, saat stress maka kecepatan waktu reaksi akan cenderung menurun, saat urutan rangsangan yang diberikan cenderung tetap maka akan meningkatkan waktu reaksi seseorang, intelegensi atau kecerdasan dalam memilih respon yang tepat juga mempengaruhi waktu reaksi dan faktor indeks massa tubuh (IMT) juga mempengaruhi, pada IMT normal akan memiliki kecepatan waktu reaksi yang lebih baik dibanding seseorang dengan IMT kurang dan IMT lebih. ${ }^{11}$

Mengingat bahwa penelitian antara variabel kognitif dan waktu reaksi auditori masih terbatas pada orang dewasa dan belum pernah diteliti pada remaja sehingga peneliti tertarik untuk melakukan penelitian antara hubungan kemampuan kognitif dan kecepatan waktu reaksi auditori pada remaja tingkat sekolah menengah atas negeri di Denpasar timur.

\section{BAHAN DAN METODE}

Penelitian ini merupakan penelitian observasi analitik dengan desain studi cross sectional. Penelitian ini dilakukan pada bulan Februari 2019 di SMAN 3 Denpasar dengan menggunakan metode pengambilan sampel yaitu cluster sampling. Jumlah sampel pada penelitian ini yaitu 51 orang. Siswa yang bersedia mengikuti penelitian secara sukarela dengan mengisi persetujuan pada inform consent dan masuk dalam kriteria inklusi yaitu memiliki indeks massa tubuh (IMT) normal dengan rentang persentil 5-85 yang diukur dengan menggunakan timbangan digital dalam satuan $\mathrm{kg}$ dan sature meter untuk tinggi badan dalam satuan $\mathrm{cm}$, berumur 16-17 tahun yang dibuktikan dengan menggunakan kartu tanda penduduk (KTP) bagi yang telah berumur 17 tahun atau menggunakan raport siswa bagi yang belum memiliki KTP serta termasuk dalam kriteria ekslusi yaitu memiliki gangguan pendengaran.

Data berupa data primer yang dikumpulkan didapatkan dari pengisian cognitive failure questionnaire. Sampel mengisi kuesioner yang terdiri dari 25 pertanyaan, dimana masing-masing pertanyaan terdiri dari 5 kolom yang harus 
dipilih salah satu. Pertanyaan 1 hingga 25 di jumlahkan hingga mendapatkan total nilai 0-100 semakin kecil nilai yang di dapat maka semakin baik kognitif dari seseorang dan sebailiknya.

Untuk mengukur kecepatan waktu reaksi auditori dilakukan dengan menggunakan millisecond software (simple auditory reaction times). Sampel melakukan tes waktu reaksi dengan meggunakan headseat pada telinga dan duduk di depan laptop saat mendengar bunyi maka dengan secepat-cepatnya menekan tombol spacebar pada laptop. Bunyi akan muncul sebanyak 20 kali dengan waktu muncul yang berbeda sehingga sampel harus berkonsentrasi saat melakukan tes ini. Tes waktu reaksi auditori ini dianggap berakhir saat sudah muncul waktu rata-rata sampel di layar laptop. Data-data yang telah dikumpulkan kemudian dianalisis dengan mengunakan bantuan software IBM SPSS 20 dengan menggunakan uji univariat, uji normalitas dengan menggunakan uji kolmogrov-sminorv dan uji bivariat menggunakan uji pearson.

\section{HASIL}

Karakteristik penelitian ini meliputi umur, jenis kelamin, waktu reaksi auditori dan kegagalan kognitif dengan melakukan uji univariat.

Tabel 1 Umur dan Jenis Kelamin Sampel

\begin{tabular}{cccc}
\hline \multirow{2}{*}{ Umur } & \multicolumn{2}{c}{ Jenis Kelamin } & \multirow{2}{*}{ Jumlah } \\
\cline { 2 - 3 } & Laki-laki & Perempuan & \\
\hline 16 & 11 & 11 & $22(43.1 \%)$ \\
17 & 15 & 14 & $29(56.9 \%)$ \\
\hline Total & $26(51 \%)$ & $25(49 \%)$ & $51(100 \%)$ \\
\hline
\end{tabular}

Tabel 1 Menunjukan bahwa sampel yang didapat berumur 16 hingga 17 tahun. Sampel yang berumur 16 tahun sebanyak 22 orang dengan 11 laki-laki dan 11 perempuan sedangkan sampel yang berumur 17 tahun berjumlah 29 tahun dengan 15 orang laki-laki dan 14 orang perempuan. Total sampel laki-laki yaitu 26 orang dan total sampel perempuan yaitu 25 orang sehingga total keseluruhan sampel yang didapat adalah 51 orang.

Tabel 2 Kegagalan kognitif, waktu reaksi auditori dan jenis kelamin

\begin{tabular}{ccc}
\hline \multirow{2}{*}{ Variabel } & \multicolumn{2}{c}{ Jenis kelamin } \\
\cline { 2 - 3 } & $\begin{array}{c}\text { Laki-laki } \\
\text { (rerata } \pm \text { simpang baku) }\end{array}$ & $\begin{array}{c}\text { Perempuan } \\
\text { (rerata } \pm \text { simpang baku) }\end{array}$ \\
\hline Kognitif & $41 \pm 8$ & $49 \pm 11$ \\
\hline Waktu reaksi auditori & $283,34 \pm 38,64$ & $319,92 \pm 78,60$ \\
\hline
\end{tabular}

Tabel 2 Menunjukan hasil persebaran kegagalan kognitif dan waktu reaksi auditori terhadap jenis kelamin didapat bahwa kognitif laki-laki didapatkan hasil rerata $41 \pm 8$ sedangkan pada perempuan $49 \pm 11$. Rerata dan simpang baku waktu reaksi auditori pada laki-laki $283,34 \pm 38,64$ sedangkan pada perempuan didapat $319,92 \pm 78,60$. Hasil yang ditampilkan pada tabel 2 menunjukan bahwa laki-laki memiliki kegagalan kognitif yang lebih kecil dibandingkan pada perempuan begitu juga pada waktu reaksi auditori laki-laki mendapatkan hasil yang lebih cepat dibandingkan dengan hasil waktu reaski auditori pada perempuan.

\begin{tabular}{cc}
\multicolumn{2}{c}{ Tabel 3 Uji Kolmogrov-Sminorv } \\
\hline Variabel & Signifikansi \\
\hline Unstandardized Residual & 0,543 \\
\hline
\end{tabular}

Uji normalitas pada penelitian ini menggunakan Teknik kolmogrov sminorv. Tabel 3. Menunjukan bahwa didapat signifikansi sebesar 0,543 yang artinya data menunjukan kriteria $>0,05$ dimana data berdistribusi normal.

Mengetahui hubungan antara kemampuan kognitif dengan waktu reaksi auditori dapat dilakukan dengan menggunakan uji bivariat dengan menggunakan teknik uji korelasi pearson. Uji korelasi ini digunakan untuk mengolah data numerik dengan numerik. Fungsi pearson correlation ( $r$ ) dan kekuatan signifikansi. Untuk mengetahui hubungan diantara variabel sekaligus mengetahui seberapa kuat hubungan antara kemampuan kognitif dengan waktu reaksi auditori Uji bivariat pada penelitian ini menggunakan Teknik pearson correlation mendapatkan hasil seperti tabel dibawah

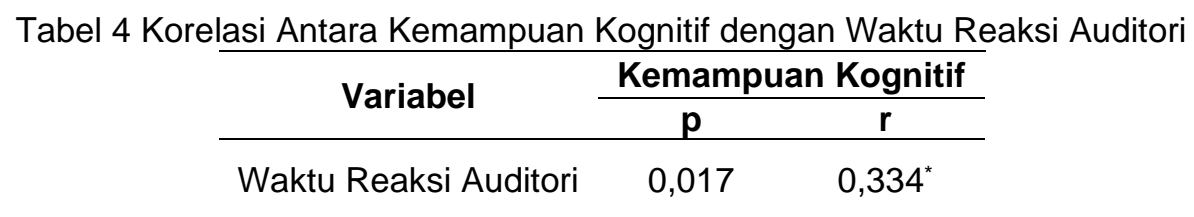

Tabel 4 Menunjukan hasil uji pearson didapat yaitu $\mathrm{p}=0,017$ dan $\mathrm{r}=0$, artinya tedapat hubungan yang signifikan antara kemampuan kognitif dengan waktu reaksi auditori pada remaja tingkat Sekolah Menengah Atas negeri di Denpasar Timur. Kolom $r$ tertera 0.334 artinya antara kemampuan kognitif dengan waktu reaksi auditori memiliki hubungan yang rendah/lemah. Tanda * (bintang) menunjukan korelasi pada signifikansi $1 \%$ atau $0.01 . \mathrm{r}$ menunjukan angka positif artinya terdapat korelasi yang searah yaitu semakin lama waktu reaksi auditori maka semakin besar skor dari Cognitive Failures Questionnaire (CFQ). 


\section{DISKUSI}

\section{Karakteristik Responden}

Hasil penelitian didapatkan bahwa pada laki-laki dan perempuan memperoleh hasil dimana laki-laki mendapatkan hasil yang lebih baik dari perempuan. Tingkat kegagalan kognitif pada laki-laki menunjukan bahwa lakilaki memiliki kegagalan kognitif yang lebih kecil dibandingkan perempuan, hal ini bisa terjadi karena perbedaan struktur pada otak baik laki-laki dan perempuan.

Saat memasuki fase remaja maka secara fisiologis akan terjadi perubahan struktur otak, seperti mielinasi, sinaptogenesis atau pemangkasan sinaptik. Hal tersebut dapat terjadi oleh karena diferensiasi hormon pada laki-laki dan perempuan sehingga struktur otak pun ikut berdiferensiasi antara laki-laki dan perempuan. Struktur otak yang dimaksud yaitu dibagian substansi abu. Luas substansia abu akan berkurang pada masa remaja. Laki-laki pada masa remaja akan memiliki luas substansia abu yang lebih luas dibanding pada perempuan sekitar $10 \%{ }^{12}$

Fungsi substansi abu adalah untuk mengolah dan menganalisis informasi yang mengandung bagian badan sel saraf, sel glia dan pembuluh kapiler sedangkan substansi putih yang terdiri dari banyak mielin sehingga berfungsi untuk menghantarkan informasi dan menghubungkan pusat-pusat informasi yang didapatkan oleh otak. Luas lokasi untuk pengolahan informasi pada laki-laki lebih besar dibandingkan perempuan maka kegagalan kognitif pada laki-laki lebih kecil dibandingkan perempuan. ${ }^{13}$

Waktu reaksi auditori laki-laki mendapatkan hasil yang lebih cepat dibanding perempuan hal ini bisa terjadi karena efek dari diferensial hormon yang dialami oleh laki-laki dan perempuan pada masa remaja. Hormon dominan pada laki-laki adalah testosteron sedangkan hormon yang dominan pada perempuan adalah esterogen. Esterogen inilah yang menyebabkan perbedaan waktu reaksi antara laki-laki dan perempuan. ${ }^{14}$

Hormon esterogen pada perempuan yang sedang dalam siklus menstruasi akan memiliki kecepatan reaksi yang lebih lambat dibandingkan laki-laki karena hormon esterogen memiliki efek penahan natrium dan air. Retensi natrium dan air ini dapat memodifikasi konduksi aksonal dan dapat mengubah ketersediaan neurotransmitter pada tingkat sinaptik sehingga esterogen akan mempengaruhi kerja motorik sensorik dengan kecepatan pemrosesan di sistem saraf pusat. ${ }^{15}$

Kemampuan kognitif dengan waktu reaksi auditori saling berhubungan karena terdapat organ-organ yang saling bekerja sama didalamnya antara lain dari sistem pendengaran, basal ganglia dan lobus otak di kortek serebri hingga otot-otot yang berkontraksi menghasilkan gerakan. Komponen dalam waktu reaksi dan kognitif secara garis besar hampir sama sehingga keduanya saling terhubung. ${ }^{16}$ Basal ganglia selain memiliki fungsi motorik juga memiliki fungsi non-motorik yaitu kognitif sehingga jika basal ganglia mengalami gangguan maka terganggu pula kemampuan motorik dan kognitifnya. ${ }^{17}$

\section{Hubungan Kemampuan Kognitif dengan Kecepatan Waktu Reaksi Auditori}

Kognitif membantu membuat hubungan yang efektif antara stimulus dan respon yang masuk dan membagi waktu reaksi menjadi tiga tahap yaitu identifikasi stimulus, pemilihan respon dan pemograman ${ }^{18}$

Waktu reaksi auditori dan kognitif ini saling berkaitan dari proses seseorang mendengar stimulus berupa suara kemudian masuk dan diolah oleh sistem pendengaran selanjutnya di olah didalam otak hingga menghasilkan keputusan untuk merespon atau mengabaikan stimulus yang datang hingga akhirnya menghasilkan gerakan. Proses inilah yang saling terkait antara waktu reaksi auditori dengan kognitif seseorang sehingga semakin cepat seseorang berpikir maka semakin cepat seseorang bertindak. ${ }^{16}$

Tahap awal suara masuk ke organ telinga dari daun telinga kemudian gelombang suara akan melintas masuk melalui saluran pendengaran lalu mengenai membran timpani atau gendang telinga pada bagian tengah. Membrane timpani bergetar sesuai dengan frekuensi getaran yang mengenainya selanjutnya menuju tingkap oval (martil, landasan, sanggurdi). Getaran dari membran timpani ditransformasi menjadi getaran tulang sanggurdi yang lebih kuat hal ini bertujuan untuk merubah gelombang suara menjadi gelombang yang bertekanan lebih besar hal ini bertujuan untuk menggerakkan cairan kental yang berada di dalam tingkap oval sehingga nantinya gendang telinga akan mampu bergerak karena terdapat udara pada kedua sisi gendang telinga hingga akhirnya informasi suara akan masuk menuju telinga dalam. Bagian koklea ada tiga yaitu skala vestibuli, skala media dan skala timpani, saat suara melewati bagian ini menyebabkan cairan pada bagian ini akan bergerak kemudian sel rambut dapat merespon perubahan posisi sekecilkecilnya perubahan maka terbukalah kanal-kanal ion pada sel rambut sehingga terjadi eksitasi sel pada saraf auditori yang merupakan bagian dari saraf kranial kedelapan. ${ }^{17}$

Informasi suara dari organ telinga tersebut akan di salurkan menuju otak tengah pada sisi kontralateral misalnya suara masuk dari telinga kanan maka akan diolah pada bagian otak tengah sebelah kiri, di otak tengah diolah dibagian superior olive, colliculus inferior, geniculate medial hingga sampai pada auditori korteks di lobus temporal pada korteks serebri. ${ }^{17}$ Fungsi colliculus inferior yaitu untuk diskriminasi pitch, pengenalan frekuensi. Ini geniculate medial untuk menganalisis kognitif lebih lanjut. ${ }^{19}$ Informasi sampai di korteks serebri tepatnya di lobus temporal superior maka informasi tersebut akan disampaikan menuju ke bagian basal ganglia tepatnya di bagian badan kaudatus atau ekor atau ujung kaudatus. ${ }^{20}$

Tahap setelah informasi suara diolah pada organ pendengaran maka selanjutnya akan diproses di otak untuk proses kognitif. Proses awal informasi akan masuk melalui nukleus kaudatus kemudian menuju basal ganglia setelah selesai kemudian akan keluar melalui globus palidus dan substansia nigra. ${ }^{21}$ basal ganglia dibagi menjadi beberapa yaitu nukleus accumbens, putamen, kaudatus, globus palidus ke empat bagian ini sering disebut korpus striatum kemudian terdapat substansia nigra dan subthalamik nucleus. ${ }^{22}$ Basal ganglia selain memiliki fungsi motorik juga memiliki fungsi non-motorik (kognitif) karena pada fungsi basal ganglia memiliki dua sirkuit yaitu sirkuit putamen yang 
berfungsi untuk mengatur gerakan motorik kompleks dan sirkuit kaudatus yang berfungsi dalam pengaturan kognitif terhadap gerakan motorik. ${ }^{21}$

Mekanisme dari sirkuit kaudatus sinyal yang berasal dari korteks serebri akan menuju nukleus kaudatus lalu di jalarkan ke thalamus ventroanterior dan ventrolateral dan akhirnya kembali ke area motorik prefrontal, premotorik dan suplementer di korteks serebri namun hampir tidak ada sinyal yang kembali menuju ke korteks motorik primer namun akan menuju regio motorik asesoris dalam area premotor dan motorik suplementer. ${ }^{23}$ Tahap ini akan menghasilkan informasi berupa instinktif untuk merespon stimulus atau informasi secara sesuai, cepat dan tepat. ${ }^{23}$

Mekanisme dari sirkuit putamen merupakan aktifitas yang dilakukan dibawah sadar diawali di area suplementer, premotor korteks motorik dan di area somatosensorik korteks sensorik kemudian jaras menuju putamen melintasi nukleus kaudatus kemudian ke bagian internal globus palidus lalu ke nukleus ventroanterior dan ventrolateral thalamus hingga akhirnya ke korteks motorik primer dan area premotorik serta area suplementer yang berkaitan erat dengan korteks motorik primer misalnya memasukkan bola basket dengan melompat. ${ }^{21}$

Tahap terakhir dari suara hingga akhirnya menghasilkan respon berupa gerakan. Informasi berupa Insting yang diperoleh dari proses selama di kortek serebri tepatnya di bagian korteks motorik selanjutnya informasi akan dibawa melalui akson dari korteks motorik melintas menuju ke batang otak yang kemudian menuju sumsum tulang. Batang otak dan sumsum tulang belakang ini yang akan menghasilkan pola aktifitas pengendali otot sedangkan peran serebellum selain berfungsi untuk keseimbangan dan mengatur koordinasi serebellum juga memiliki peran untuk mengatur kecepatan gerakan, setelah informasi dan pola gerakan selesai diproses akhirnya informasi tersebut akan dibawa pada otot untuk akhirnya otot berkontraksi hingga menghasilkan sebuah gerakan. ${ }^{17}$

Mekanisme yang telah dijelaskan tersebut dapat dilihat bahwa meskipun dengan sistem yang sedemikian rumit dari proses stimulus suara yang masuk hingga menghasilkan gerakan kerja otak bisa begitu cepat dan dapat dilihat antara kognitif dan kecepatan waktu reaksi auditori saling bekerja sama satu dengan yang lainnya sehingga jika seseorang mengalami gangguan kognitif maka kecepatan waktu reaksi auditori nya pun akan ikut terganggu.

\section{SIMPULAN}

Hasil penelitian yang telah dilakukan, maka dapat disimpulkan bahwa terdapat hubungan antara kemampuan kognitif dengan waktu reaksi auditori pada remaja tingkat sekolah menengah atas negeri di Denpasar Timur.

\section{DAFTAR PUSTAKA}

1. Sary, Y. Perkembangan Kognitif Dan Emosi Psikologi Masa Remaja Awal. J Pengabdi Kepada Masyarakat; 2017;1(1):6-12.

2. Wahida, S. Problematika Kenakalan Remaja Dan Upaya Solusinya Di Desa Tanjunganom Kecamatan Gabus Kabupaten Pati (Analisis Fungsi Bimbingan Agama Islam). skripsi, 2017

3. Kurniasih. Hubungan Antara Berpikir Positif Dan Kreatif Dengan Kemampuan Pemecahan Masalah Pada Remaja. Skripsi; 2008:5

4. Komarudin. Membentuk Kematangan Emosi Dan Kekuatan Berpikir Positif Pada Remaja Melalui Pendidikan Jasmani. Jurnal Pendidikan Jasmani Indonesia: 2016;12.

5. Putri, Diah. Prevalensi Stres Psikososial Dan Faktor - Faktor Yang Mempengaruhi Pada Siswa - Siswi Kelas Xii Studi Pendidikan Ipa Dan Ips Sman 6 Denpasar. E-Jurnal Med Udayana;2014;1.

6. Prabhavathi,K. Hemamalini,R. V, G TK, Amalraj,C. Maruthy, K.N. Saravanan,A. A correlational study of visual and auditory reaction time with their academic performance among the first year medical students. National Journal of Physiology, Pharmacy and Pharmacology;2017;7(May):370-4.

7. Fuji. 2017. Pengertian kognitif menurut para ahli. Tersedia Https:/Www.Trigonalmedia.Com/2017/09/PengertianKognitif-Menurut-Para-Ahli.Html (diakses tanggal 10 november 2018)

8. Khusumah, A.A. hubungan tingkat Pendidikan ibu dengan perkembangan kognitif pada anak umur prasekolah di desa gandrung manis kecamatan gandrungmangu kabupaten cilacap. Universitas Muhammadiyah purwokerto. Fakultas kesehatan. Cilacap; Repository.Ump.Ac.Id.

9. Kosinski, R, J.2008. a literaturereview. Http://Www.Fon.Hum.Uva.NI/Rob/Courses/Informationinspeech/Cdrom/Literature/Lotwinterschool2006/Biae.Clem son.Edu/Bpc/Bp/Lab/110/Reaction.Htm (diakses tanggal 9 November 2018)

10. Baayen, R. Millin, P.2010. Analyzing reaction times. International journal of psychological research. Tersedia Www. Sfs. Uni-Tuebingen.De/ Hbaayen/Publications/Baayenmilin 2010.Pdf (diakses tanggal 9 november 2018)

11. Helena.2016. factors affectin reaction time. Tersedia Http://Www.Cti-Home.Com/WpContent/Uploads/2014/01/Factors-Affecting-Reaction-Time1.Pdf (diakses tanggal 10 november 2018)

12. Blakemore, S. Choudhury, S. Development of the adolescent brain: implications for executive function and social cognition. Journal ofChild Psychology and Psychiatry;2006;4(3): 296-312.

13. Aha. 2017. Ilmu dasar. Tersedia Https://Www.Ilmudasar.Com/2017/05/Pengertian-Struktur-Dan-FungsiCerebellum-Adalah.Html (diakses tanggal 8 Desember 2018)

14. Dykiert.D, Der.G, M.John, Deary.J. Sex Differences in Reaction Time Mean and Intraindividual Variability Across the Life Span. American Psychological Association;2012;45(5);1263-1276.

15. Namita.ranjan, sheni.D.N. a comparative study of auditory and visual reaction time in males and femalesstaff during shift duty in hospital. Biomedical rsearch;2010;199-203.

16. Kylonen.P, Zu. J, Use of Response Time for Measuring Cognitive Ability.Journal of intelligence;2016;4(14): 1-29.

17. Kalat, J. Biopsikologi (9). Jakarta: Salemba Humanika. 
18. Alikhani, H., Vaezmousavi. M, Mokhtari, P. the effect of cognitive and motivational imagery on Choice reactin time. Word applied sciences journal;792-796

19. Hilfiger. 2018. Apa itu colliculus inferior. http://anna.chiepunto.com/apa-itu-colliculus-inferior/ (diakses tanggal 8 desember 2018)

20. Joe $\lim$. S, Fiez.J, Holt. Lori. How may the basal ganglia contribute to auditory categorization and speech perception?. frontiers in neuroscience;2014;8(230);1-18.

21. Johan. 2018. Anatomi ganglia basalis. Tersedia https://docplayer.info/72951232-Anatomi-ganglia-basalis.html (diakses tanggal 8 Desember 2018)

22. Knierim.J. 1997. Chapter 4: basal ganglia. Tersedia https://nba.uth.tmc.edu/neuroscience/m/s3/chapter04.html (diakses tanggal 15 desember 2018). 